\title{
PELATIHAN BATIK LILIN DINGIN DENGAN VISUAL CIRI KHAS BETAWI DI RUMAH SINGGAH BINA ANAK PERTIWI JAKARTA
}

\author{
Gilang Cempaka ${ }^{1}$, Ayoeningsih Dyah ${ }^{2}$ \\ Program Studi Desain Komunikasi Visual, Fakultas Ilmu Rekayasa, Universitas Paramadina Jakarta \\ e-mail : gilang.cempaka@paramadina.ac.id
}

\begin{abstract}
Community service by Visual Communication Design (DKV) Paramadina University is aims to developing skills for the member of residents at the "Rumah Singgah" Bina Anak Pertiwi. It has around 166 children and 377 adults. They generally come from street who do not have a decent life. The training is taught batik through cold wax media on cloth, with visual characteristics of Betawi culture. DKV empowering member of residents through improving skills in batik. Besides abilities in digital technology, hand skills with creativity are believed still survive and become the backbone of the creative industry in the 4.0 era. The activity method is to provide training with practicing, apply cold waxed batik with the visuals of Betawi's icons. This activity was attended by around fifteen member residents. Through this training, batik can be developed into various kinds of products such as scarves, tablecloths, souvenirs and other home decorations. Making batik with cold wax is relatively easy to apply, and the materials are easy to get. So it is hoped that the member residents can innovatively develop their own skills and creativity. They are expected to be more productive so that they can improve their economic level.
\end{abstract}

Key words: batik, cold wax, Betawi culture

\section{Pendahuluan}

\section{Profil Rumah Singgah Bina Anak Pertiwi}

Rumah singgah adalah salah satu program yang digagas oleh Kementrian Sosial Republik Indonesia sebagai tempat penampungan sementara anak jalanan dan kalangan terlantar. Sejumlah Rumah Singgah yang ada di Jakarta umumnya berkonsentrasi sebagai tempat pertemuan antara pekerja sosial dengan anakanak jalanan, pusat assessment, rujukan dan fasilitator dengan lembaga lain, sekaligus sebagai tempat perlindungan. Program kegiatan yang dilakukan di Rumah Singgah umumnya adalah bantuan pendidikan kepada anak-anak jalanan melalui program beasiswa, penyediaan berbagai kegiatan ketrampilan, program pendampingan pada kegiatan usaha ekonomi produktif (UEP), pembentukan Kelompok-Kelompok Usaha Bersama, sekaligus sebagai tempat bimbingan mental dan spiritual.Rumah Singgah Bina Anak Pertiwi yang berlokasi di Jl. Bacang Rt 09/RW 01 No. 46 Kelurahan Jati Padang Kecamatan Pasar Minggu, Jakarta Selatan, di bawah pimpinan Ali Santoso., SH memiliki anak binaan sekitar 166 orang dan warga binaan dewasa berjumlah 377 Orang. Warga binaan di tempat ini umumnya berasal dari kaum jalanan yang tidak memiliki kehidupan yang layak, umumnya profesi mereka adalah pemulung, pengamen dan mayoritas adalah pengangguran, yang umumnya tidak memiliki keterampilan dan wawasan. Mereka berada di rumah Singgah untuk mendapatkan pendampingan agar mereka dapat bertahan di hidup di Jakarta. Mereka butuh keterampilan sebagai bekal untuk kelak dapat hidup mandiri. Untuk itu, diperlukan sinergisitas antara kepentingan lembaga dengan kebutuhan masyarakat, agar program yang direncanakan oleh lembaga merupakan cerminan dari kebutuhan murni serta harapan segmen-segmen masyarakat.Berdasarkan hasil survey lapangan dan wawancara oleh tim, terdapat beberapa permasalahan yang ditemukan pada Rumah Singgah Bina Anak Pertiwi yang dipilih sebagai Mitra, diantaranya : belum maksimalnya program kemitraan yang dilakukan oleh lembaga akademik, untuk memberikan pendampingan guna memberikan 
keterampilan yang dapat memberikan peningkatan ekonomi dan keterampilan warga binaan pada kalangan usia produktif. Berdasarkan pemetaan di atas, permasalahan mitra dirangkum di bawah ini :

1. Mitra membutuhkan program/kegiatan yang dapat bersifat menambah keterampilan warga binaan.

2. Mitra membutuhkan pendampingan untuk mengembangkan keterampilan tersebut menjadi sebuah produk bernilai ekonomi.

3. Mitra harus dibina agar dapat memaksimalkan semua potensi warga binaan, hingga kelak dapat menjadi warga mandiri dan mampu meningkatkatkan kualitas hiduo keluarga melalui keterampilan yang dimiliki.

Melihat pada kondisi lapangan pada Mitra Rumah Singgah Bina Anak Pertiwi, maka solusi yang akan diberikan pada kegiatan ini adalah :

a. Akan diberikan wawasan dan pendampingan bagaimana melakukan pegembangan untuk melahirkan aneka souvenir yang dihasilkan dari teknik batik lilin dingin.

b. Bentuk pelatihan yang akan diberikan dalam bentuk pelatihan langsung dengan durasi waktu yang telah ditentukan, dengan teknik yang mudah dipelajari hingga warga binaan kelak dapat mengembangkan secara mandiri.

c. Prodi DKV UPM akan membantu warga binaan untuk mengembangkan produk yang akan bernilai ekonomi, sebagai upaya agara warga binaan mandiri secara ekonomi.

Kegiatan pengabdian masyarakat (pengmas) serupa yang pernah dilaksanakan penulis bersama tim di antaranya dalam Festival Seni di Tiempo Iberno Americano, Fukuoka Jepang tahun 2018, yang diikuti oleh sejumlah peserta internasional (https://bisniswisata.co.id/komunitas-22-ibu-kenalkan-teknik-batikklungsu-di-fukuoka/). Selain itu workshop batik lilin dingin dilaksanakan dari hasil kerjasama antara Komunitas 22 Ibu dengan Medco di tahun 2017, bebarengan dengan kegiatan pameran, dimana penulis adalah anggota dari komunitas (https://www.beritasatu.com/gaya-hidup/469368/medco-group-gelarworkshop-dan-pameran-batik-lilin-dingin). Peserta umumnya tertarik dan antusias dalam mengembangkan kreasi batik dengan lilin dingin karena dianggap lebih mudah dibanding teknik batik konvensional/canting, jadi kreatifitas bisa lebih tak terbatas.

Di era revolusi 4.0, segala sektor kehidupan berbasiskan teknologi digital, ditandai dengan jumlah tenaga kerja menurun akibat digantikan mesin dan internet, namun keterampilan berbasis kreatifitas masih tetap dibutuhkan karena tidak akan tergantikan oleh mesin. Staf Ahli Menteri Pendidikan dan Kebudayaan Bidang Inovasi dan Daya Saing Ananto Kusuma Seta menjelaskan, jenis pekerjaan yang belum bisa digantikan oleh mesin atau robot adalah jenis pekerjaan bersifat analitik dan interpersonal, seperti seniman dan budayawan (penulis lagu, pemusik, penari, desainer, pemasak, dan lainnya) (https://nasional.sindonews.com/read/1388305/15/tiga-skills-diperlukan-untuk-hadapi-revolusi-industriera-40-1553038602). Oleh karena itu jenis keterampilan yang berbasiskan seni budaya seperti membatik dengan media lilin dingin yang memerlukan keterampilan tangan dan kreatifitas bisa menjadi bekal dalam menyongsong era industri 4.0 karena tidak bisa digantikan oleh mesin. Selain itu kreativitas yang melibatkan keterampilan tangan dan inovasi dianggap masih bisa menjadi tulang punggung dalam industri kreatif kedepannya.

\section{Batik Teknik Lilin Dingin}

Berbeda dengan teknik batik tradisional, batik teknik lilin dingin adalah teknik batik yang tidak menggunakan lilin (malam/wax) dan canting. Pengganti lilin (malam/wax) adalah dari butiran biji asam Jawa yang dihancurkan menjadi seperti tepung, margarin dan air hangat dalam takaran tertentu sehingga berwujud (http://balittri.litbang.pertanian.go.id/index.php?option=com_content\&task=view\&id=75\&Itemid=1\&lang =ba). Kesamaan hanya dari aspek kain sebagai material utama. Pada teknik ini, penggunaan jenis kain 
dibeda. kan berdasar pewarna tekstil yang akan digunakan. Jenis kain yang dapat digunakan dan pewarna yang dapat digunakan klasifikasinya dapat dilihat pada tabel di bawah ini :

\begin{tabular}{|c|c|c|}
\hline Jenis Serat & Nama Kain & Jenis warna \\
\hline Serat alam & Sutra, Katun, Wol & Naptol, Indigosol, Reaktif \\
\hline Serat sintetis & Polyester, Nylon & Pewarna Dispersi \\
\hline
\end{tabular}

Alat bantu yang digunakan pada proses membutan batik dengan teknik ini adalah sebagai berikut :
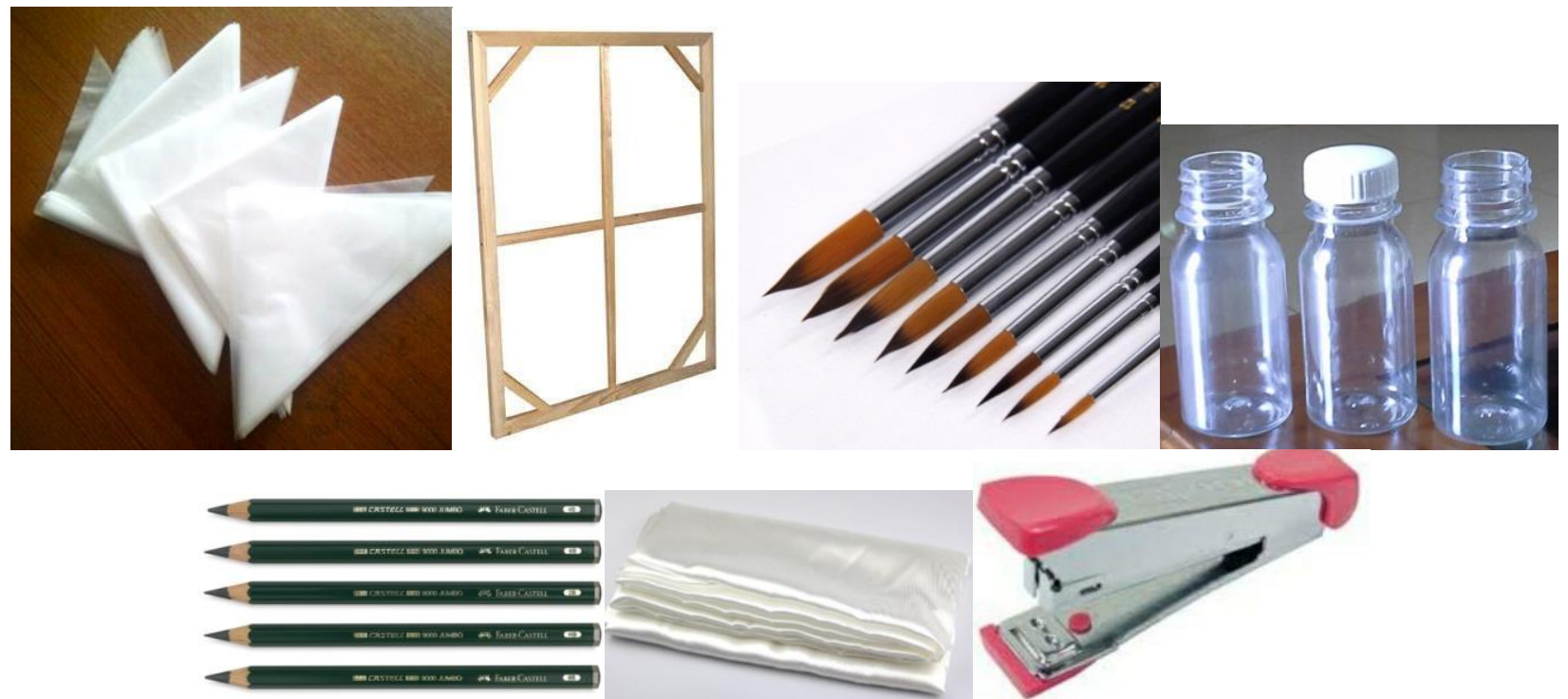

Gambar 1. Pastik segitiga untuk menyimpan lilin dingin, spanram, kuas, botol untuk menyimpan warna, pinsil, kain dan streples

(sumber : istimewa)

\section{Metode}

Kegiatan pengmas dilaksanakan selama tiga hari berturut-turut yaitu tanggal 2-5 Januari 2019 di Rumah Singgah Bina Pertiwi, materi yang diberikan diupayakan bersifat aplikatif dan mengarah pada objek langsung untuk pengembangan keterampilan dari warga binaan. Tahapannya adalah sebagai berikut :

1. Pihak tim Universitas Paramadina akan memberikan wawasan tentang ragam visual ciri khas Betawi yang akan dikembangkan pada aneka produk yang dapat diapliksikan dari pelatihan batik lilin dingin.

2. Pihak tim Universitas Paramadina akan memberikan pengenalan menggambar ragam visual ciri khas Betawi dengan menggambar langsung atau tracing/menjiplak.

3. Pihak tim Universitas Paramadina akan memperkenalkan pada Mitra dan warga binaan aneka alat dan bahan serta teknik produksi, dan aneka desain. 
Universitas Paramadina menempatkan diri sebagai fasilisator untuk memberi pembekalan berupa workshop batik lilin dingin yang dapat diaplikasikan pada aneka produk yang dapat dijadikan benda ekonomis dan memiliki nilai jual, dan mendorong lahirnya jiwa kewirausahaan pada warga binaan mitra.

\section{Hasil Dan Pembahasan}

Diawali dengan survey ke lokasi Rumah Singgah Yayasan Bina Anak Pertiwi, yang berada di dalam gang, diantara rumah-rumah penduduk yang padat. Di lantai satu terdapat aula seluas kurang-lebih 10x5 meter, yang berfungsi sebagai kelas untuk murid-murid PAUD dan Taman Kanak-Kanak. Terdapat meja, kursi, white board, dan tempat berwudhu di dalamnya, cukup memadai sebagai tempat pelaksanaan pengmas. Warga binaan atau peserta pengmas adalah para ibu pengajian Yayasan Bina Pertiwi, yang tinggal di dekat lokasi rumah singgah dengan jumlah maksimal 15 orang.

\section{Wawancara}

Proses komunikasi diawali melalui wawancara kepada pimpinan yayasan yaitu Sdr. Ali Santos., SH, dan untuk lebih mengetahui kebutuhan peserta di sana dilakukan pengecekan sarana dan prasarana. Disepakati warga binaan atau peserta pengmas adalah para ibu pengajian Yayasan Bina Pertiwi, yang tinggal di dekat lokasi rumah singgah dengan jumlah maksimal 15 orang. Diharapkan para ibu tersebut bisa mengisi waktu luang dengan kegiatan positif bernilai ekonomi, sekaligus belajar berkreasi melalui media batik lilin dingin. Kegiatan wawancara ini kemudian ditindaklanjuti dengan penandatanganan MoU antara Dekan Fakultas Ilmu Rekayasa dengan Pimpinan Yayasan Bina Anak Pertiwi pada tanggal 2 Januari 2019.

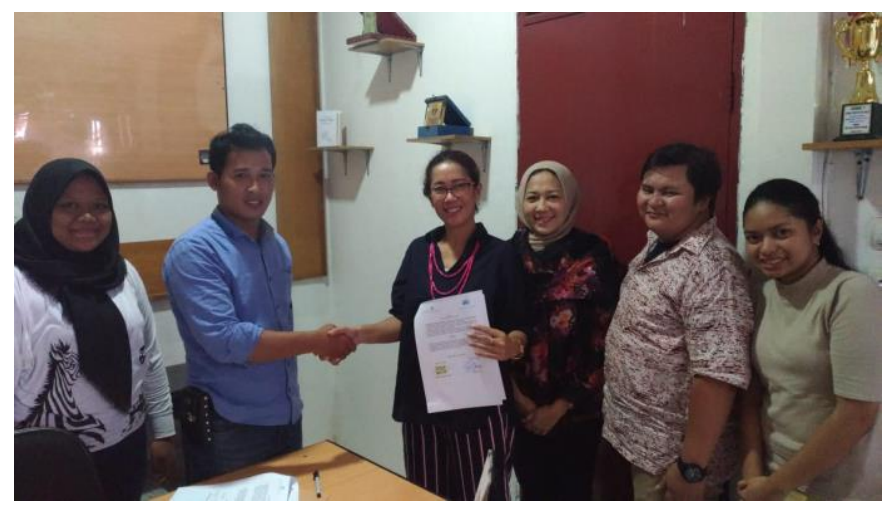

Gambar 2. Kesepakatan kerjasama Fakultas Ilmu Rekayasa denganYayasan Rumah Singgah Bina Pertiwi (sumber : pribadi)
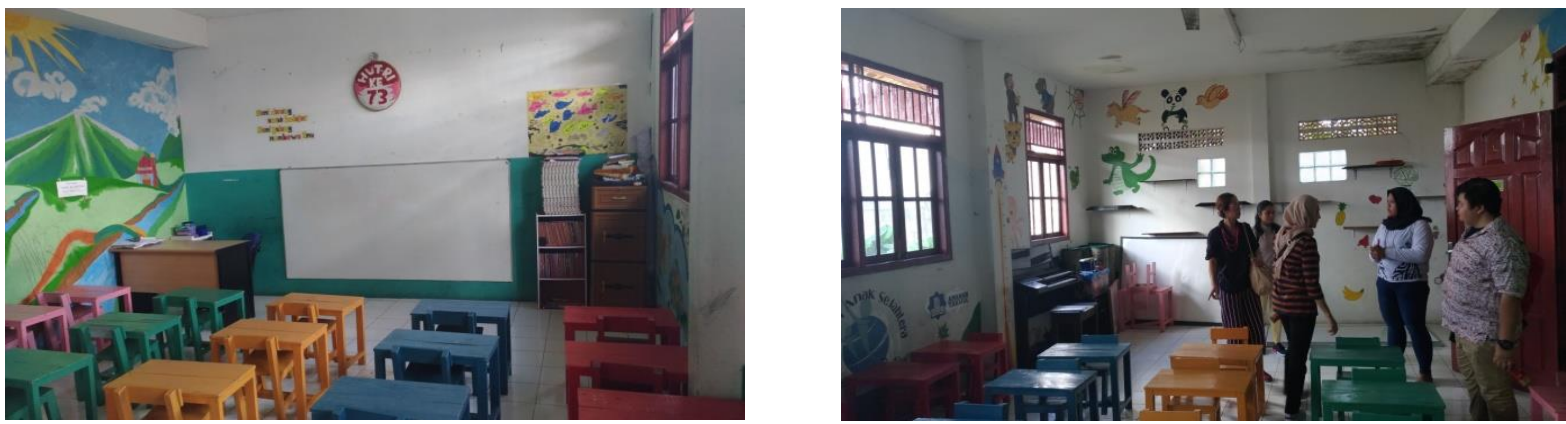

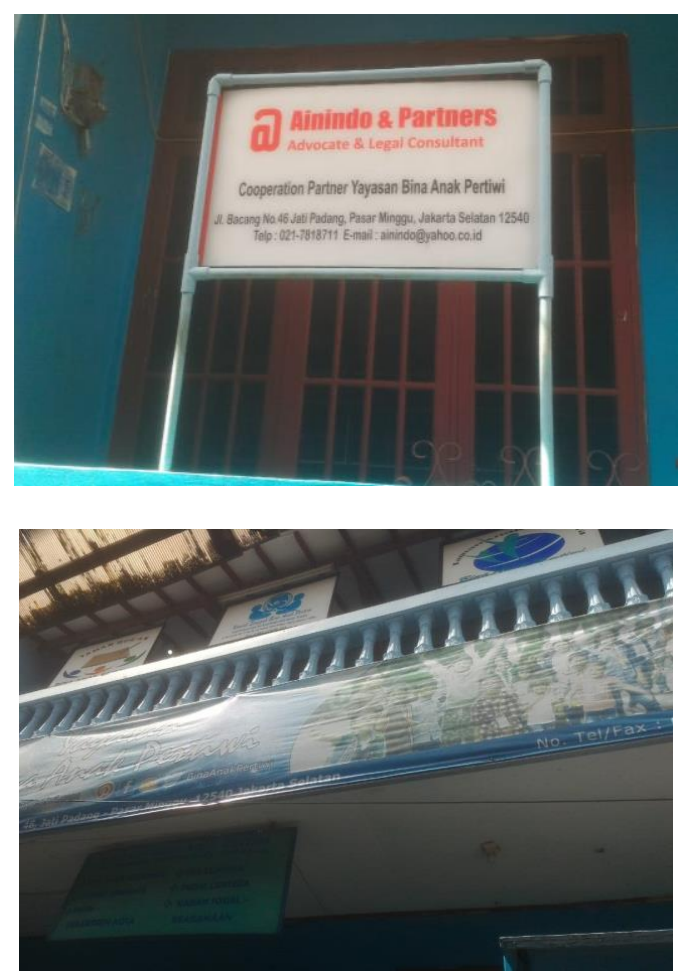

Gambar 3, 4, 5, 6. Lokasi dan kondisi Rumah Singgah (sumber : pribadi)

\section{Pelaksanaan}

\section{a. Hari Pertama}

Pelaksanaan dilakukan pada tanggal 2 Januari 2019, pukul 14.00 hingga selesai. Peserta sebanyak 15 orang, telah hadir dan mendengarkan paparan tentang kegiatan ini dan manfaat yang akan didapat untuk pengembangannya kelak. Program hari pertama pada warga binaan adalah adalah :

1. Pengenalan alat dan bahan membatik.

2. Menjelaskan batik dan pengembangan kreasi batik untuk dijadikan benda aplikatif, misalnya taplak, syal, hiasan dinding, souvenir, dan lain-lain.

3. Pengenalan motif batik, terutama motif batik Betawi.

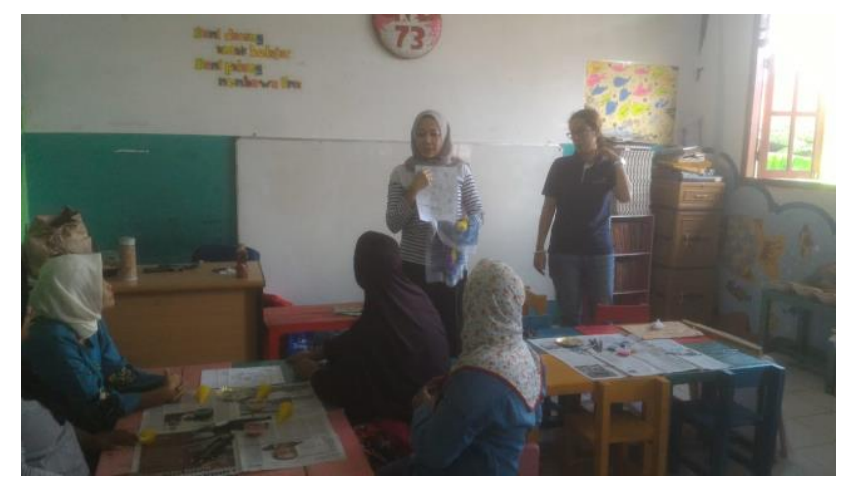




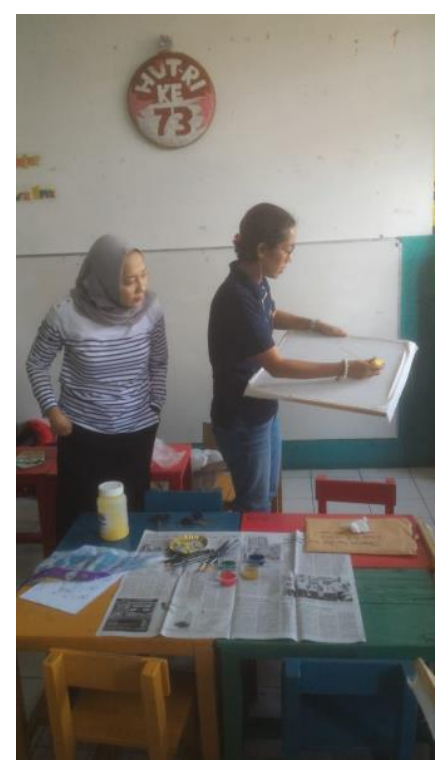

Gambar 7 dan 8. Pengenalan dan pengaplikasian teknik batik dengan lilin dingin (sumber: pribadi)

b. Hari kedua

Program hari kedua adalah praktika tentang beberapa materi, dari pukul 10.00 sampai selesai, diantaranya:

1. Menjelaskan teknik pemasangan kain pada frame (pamidangan) agar siap digambar .

2. Menggambar motif batik Betawi dengan pinsil pada kain yang telah dibentangkan di frame berukuran $50 \times 50 \mathrm{~cm}$, contoh motif batik Betawi dibagikan pada warga binaan agar diikuti/tracing.

3. Mengaplikasikan lilin dingin diatas sketsa di atas kain.

4. Mewarnai kain yang telah digambari oleh lilin dingin dengan cat pigmen dan kuas.

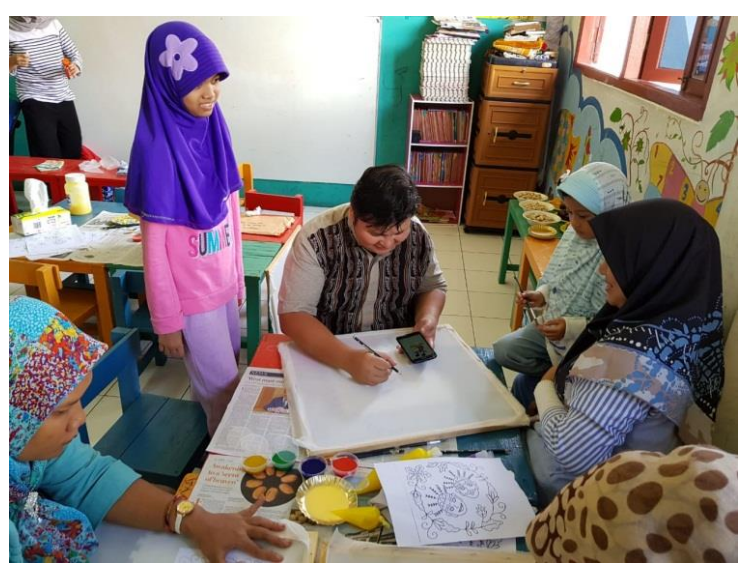

Gambar 9. Menggambar motif batik dengan pinsil ke atas kain (sumber : pribadi) 


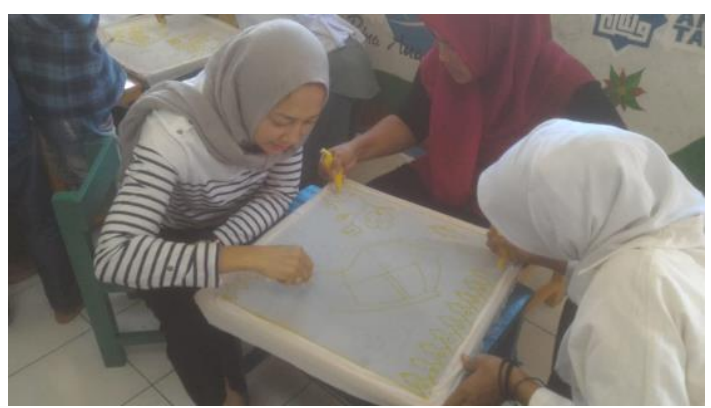

Gambar 10. Mengaplikasikan lilin dingin keatas sketsa motif batik (sumber : pribadi)

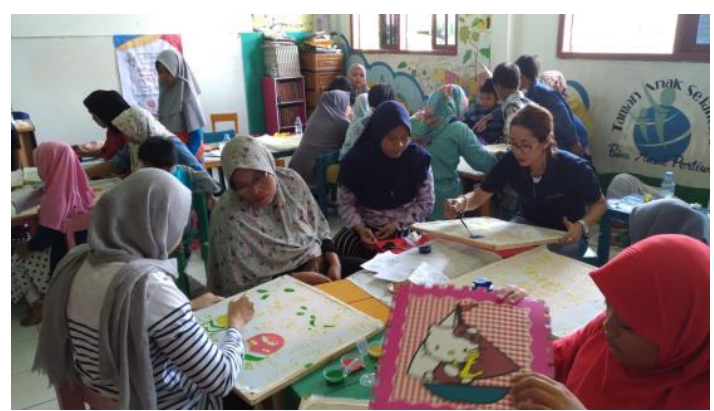

Gambar 11. Proses mewarnai batik (sumber : pribadi)

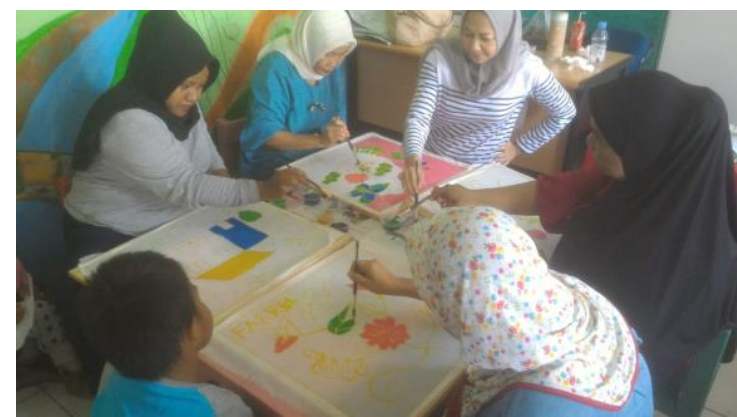

Gambar 12. Proses mewarnai batik (sumber : pribadi)

c. Hari ketiga

Program hari ketiga dimulai pukul 10.00 adalah tahap akhir dari proses batik (finishing) yaitu :

1. Melepaskan kain-kain dari frame, dan menyertika kain-kain tersebut dengan suhu panas, bertujuan agar warna pigmen kain menjadi "matang" dan tidak luntur bila terkena air.

2. Mencuci kain-kain yang telah disetrika (melorod), bertujuan agar lilin dingin yang menepel di atas kain luruh.

3. Mengeringkan kain tersebut dengan cara diangin-angin/jemur, sehingga kain siap dipergunakan. 


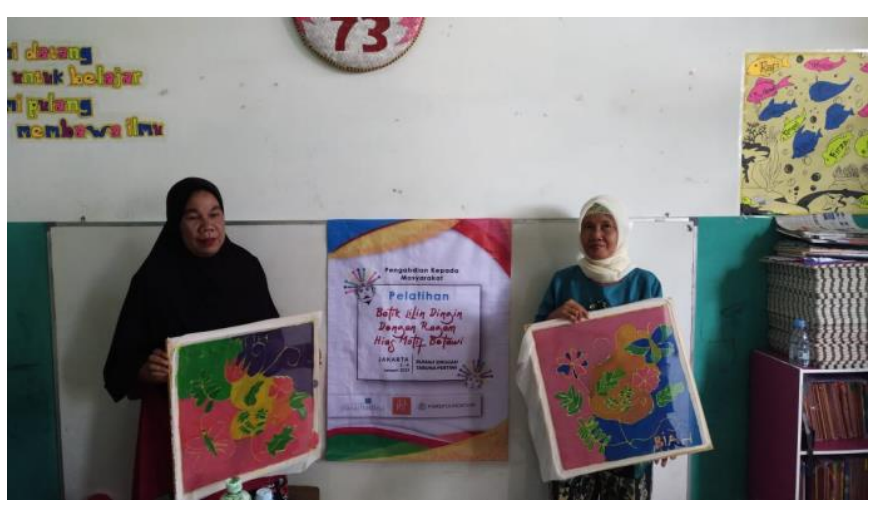

Gambar 13. Hasil kreasi batik warga binaan (sumber : pribadi)

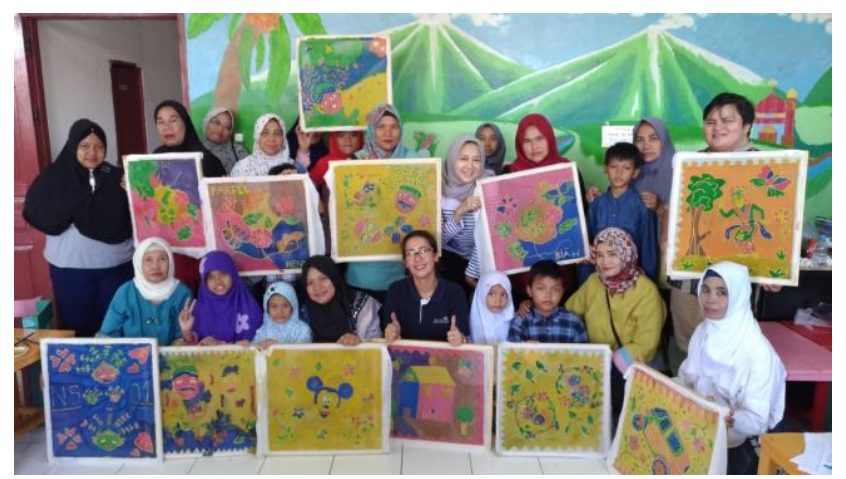

Gambar 14. Hasil kreasi batik warga binaan

(sumber : pribadi)

\section{Hasil dan Luaran yang Dicapai}

Hasil dan luaran yang diharapkan adalah warga binaan yang terdiri dari para ibu rumah tangga mengenal praktek membatik dengan menggunakan media lilin dingin dengan visual ikon budaya Betawi. Karena selama ini warga binaan umumnya hanya mengetahui teknik membatik dengan cara konvensional yaitu menggunakan canting dan lilin panas. Karena pelatihan ini adalah hal yang pertama kalinya untuk warga binaan maka indictor keberhasilan dari pengmas ini lebih ke tahap pengenalan/awareness.

Hal ini sesuai dengan hasil wawancara antara tim dengan beberapa warga binaan setelah selesai melaksanakan pelatihan. Ibu Mulyani (34 tahun), mengatakan bahwa ia baru mengetahui Teknik batik dengan lilin dingin saat pelatihan ini, namun ia agak kesulitan dalam mengaplikasikan lilin dingin mengikuti pola batik yang ada di atas kain sehingga perlu banyak dibantu. Ibu Ika (28 tahun) belum pernah mencoba praktek membatik, ia baru pertama kali membatik di pelatihan ini, ikon budaya Betawi sudah sangat familiar baginya, dan ia setuju bila ikon tersebut bisa dikembangkan di motif batik dengan Teknik lilin dingin. Ibu Supeni (45 tahun) mengatakan bahwa membatik dengan lilin dingin relatif mudah, peralatannya pun mudah didapatkan, ia ingin mempelajari lebih lanjut mengenai teknik batik dengan lilin dingin untuk dijual. Untuk itu dapat disimpulkan bahwa hasil dan luaran yang dicapai adalah sebagai berikut :

1. Warga binaan menjadi tahu mengenai teknik batik lilin dingin.

2. Warga binaan mengetahui ikon budaya Betawi sebagai dapat dikembangkan dalam pola batik.

3. Warga binaan mengenal teknik menggambar baik secara langsung maupun menjiplak/tracing.

4. Warga binaan mengetahui peralatan, bahan dan teknik membatik dengan lilin dingin, dimulai dari pengenalan alat dan bahan, menggambar kain dengan pinsil, aplikasi lilin dingin, mewarnai dengan cat pigmen, sampai tahap finishing. 
5. Warga binaan mengetahui mengembangan dari kreasi batik lilin dingin menjadi produk aplikatif atau souvenir yang memiliki nilai ekonomi seperti taplak, syal, pakaian, hiasan dinding dan lainlain.

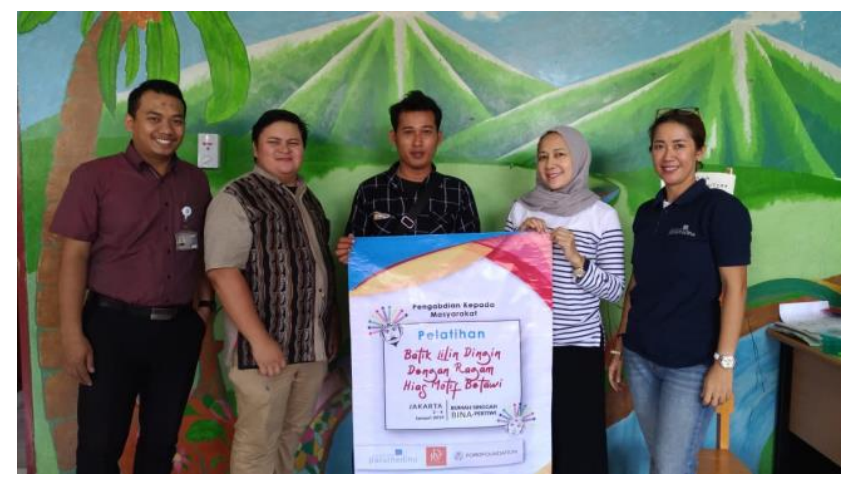

Gambar 15. Foto bersama pimpinan Yayasan Rumah Singgah Bina Pertiwi (sumber : pribadi)

\section{Kesimpulan}

1. Program pengmas pengenalan dasar batik lilin dingin yang didukung oleh kemitraan Prodi DKV Universitas Parmadina dan Ford Foundation telah terlaksana dengan baik dan mendapat antusiasme dari warga binaan.

2. Prodi DKV telah meninggalkan beberapa alat dan bahan di rumah singgah, sehingga diharapkan warga binaan dapat mengembangkan kreasi batik dengan lilin dingin secara mandiri, mengingat secara teknis relatif mudah dilaksanakan.

\section{Saran}

1. Sebaiknya ada pelatihan yang berkelanjutan, yang dimulai dari meningkatkan keterampilan teknis menggambar dan mewarnai di atas batik, sehingga skill warga binaan dalam berkreasi batik bisa lebih berkembang.

2. Program selanjutnya adalah pengembangan desain atau aplikasi batik diberbagai macam produk yang bisa dijual ke masyarakat, sehingga kreasi batik warga binaan bisa bernilai ekonomi.

3. Ada kerjasama dengan UKM setempat, agar warga binaan dapat dengan mudah menjual hasil kreasinya.

\section{Ucapan Terima Kasih}

Penulis mengucapkan terima kasih kepada Universitas Paramadina dan Ford Foundation yang telah memberi dukungan financial terhadap penelitian ini.

\section{Daftar Pustaka}

Bahan presentasi Workshop Batik Ekplorasi Bubur Tamarin, Komunitas 22 Ibu, Bandung http://balittri.litbang.pertanian.go.id/index.php?option=com_content\&task=view\&id=75\&Itemid=1\&la $\underline{\text { ng}}=\mathrm{ba}$ https://bisniswisata.co.id/komunitas-22-ibu-kenalkan-teknik-batik-klungsu-di-fukuoka/ 
https://nasional.sindonews.com/read/1388305/15/tiga-skills-diperlukan-untuk-hadapi-revolusi-industriera-40-1553038602.

http://news.liputan6.com/read/185250/biji-asam-dikembangkan-menjadi-pengental-tekstil http://www.academia.edu/9646415/EKSTRAKSI_POLISAKARIDA_PADA_BIJITTAMARIND

https://www.beritasatu.com/gaya-hidup/469368/medco-group-gelar-workshop-dan-pameran-batik-lilindingin 